\title{
Indeterminate Peri-Neural Invasion
}

National Cancer Institute

\section{Source}

National Cancer Institute. Indeterminate Peri-Neural Invasion. NCI Thesaurus. Code C160695.

An indication that the perineural invasion is indeterminate. 